\title{
Adsorption of Phosphate Ions from Aqueous Solution of Nickel Hydroxides Calcined at Different Temperatures
}

\author{
Fumihiko Ogata and Daisuke Imai \\ Faculty of Pharmacy, Kinki University 3-4-1 Kowakae, Higashi-Osaka, Osaka 577-8502, Japan \\ Megumu Toda and Masashi Otani \\ Kansai Catalyst Co., Ltd. 1-3-13, Kashiwagi-cho, Sakai-ku, Sakai, Osaka, 590-0837, Japan \\ Naohito Kawasaki* \\ Faculty of Pharmacy, Kinki University 3-4-1 Kowakae, Higashi-Osaka, Osaka 577-8502, Japan.
} (Received 5 June 2014; Accepted 17 June 2014; Published 30 August 2014)

\begin{abstract}
Nickel hydroxide (Ni100) and nickel hydroxide, including cobalt (NiCo91), were calcined at different temperatures. These materials were investigated by analyzing data obtained from X-ray diffraction (XRD), scanning electron microscopy, specific surface area, thermogravimetric-differential thermal (TG-DTA) technique, and electron-probe microanalysis. The XRD and TG-DTA data obtained indicated that calcination at $250-270^{\circ} \mathrm{C}$ can promote the conversion of $\mathrm{Ni}(\mathrm{OH})_{2}$ into $\mathrm{NiO}$, and that cobalt hardly affected the structural changes of nickel hydroxide. The specific surface areas of Ni100 and $\mathrm{NiCo} 91$ were determined to be in the range $17.9-148.3$ and $21.0-145.1 \mathrm{~m}^{2} / \mathrm{g}$, respectively. The specific surface area increased suddenly at $260^{\circ} \mathrm{C}$. The amount of phosphate adsorbed onto Ni100 and NiCo91 was measured to be in the range $29.2-44.7$ and $29.7-54.0 \mathrm{mg} / \mathrm{g}$, respectively. The amount adsorbed onto Ni100 or NiCo91 was greater than that onto another adsorbent previously reported. The correlation coefficient relationships between the specific surface areas of Ni100 and NiCo91 and the saturated amount of the adsorbed phosphate ions were found to be 0.935 and 0.960 , respectively. These results suggested that adsorption of phosphate ions with Ni100 or NiCo91 is related to the specific surface area. Our study demonstrated that Ni100 and NiCo91 can be considered as promising materials for the adsorption of phosphate ions from aqueous solutions.[DOI: 10.1380/ejssnt.2014.404]
\end{abstract}

Keywords: Nickel; Cobalt; Adsorption; Phosphate ion

\section{INTRODUCTION}

Phosphate is an essential macronutrient in aquatic environments; however, when present in excess, it can cause eutrophication of reservoirs, lakes, and coastal areas [1]. Thus, effluent concentration of phosphate from wastewater-treatment facilities and industrial plants must be controlled with chemical and biological techniques to meet the discharge limits $[2,3]$. In the past decades, several approaches for phosphorus removal from wastewater have been developed, including precipitation through chemical methods, active sludge, ion exchange, and phosphate crystallization [4-8]. Although highly effective for phosphorus removal, these techniques have serious drawbacks such as high costs, low efficiency, and nontrivial implementation. To solve these problems, adsorption is being increasingly used in research on phosphorus removal because of its high efficiency and relatively simple application. Thus, diverse adsorbents have been used for phosphorus removal, such as Kanuma mud, $\mathrm{Mg}_{3}-$ Fe layered double hydroxides, hydrous manganese oxide, and grapheme-nanosheet-supported lanthanum hydroxide nanoparticles [4, 9-11]. Nickel hydroxide and nickel oxide materials have received much attention in recent years for application in alkaline secondary batteries, fuel cells, electrochemical capacitors, electrolyzers, electrosynthetic cells, and electrochromic devices [12-16]. Rechargeable alkaline nickel batteries (e.g., Ni/Cd, Ni/Fe, Ni/Zn, Ni/H $\mathrm{H}_{2}$, and $\mathrm{Ni} / \mathrm{MH}$ ) are usually positive limited, i.e., the capacity and cycle life of the cells are mainly determined by the

\footnotetext{
* Corresponding author: kawasaki@phar.kindai.ac.jp
}

properties of nickel electrodes [17]. Driven by a high commercial demand, several methods have been developed to improve the preparation and discharge of the active materials of nickel hydroxide electrodes for rechargeable nickel batteries [18]. Despite these efforts, nickel hydroxide and nickel oxide are not extensively used. Moreover, purification of wastewater (adsorption of phosphate ions from aqueous solutions) by nickel hydroxide or nickel oxide has never been reported. Thus, if methods for purification of wastewater based on nickel hydroxide and nickel oxide could be developed, the value and the application range of these materials would drastically increase. In this study, the properties of nickel hydroxide (Ni100) and nickel hydroxide, including cobalt ( $\mathrm{NiCo} 91)$, calcined at different temperatures were investigated and their adsorption capability of phosphate ions evaluated.

\section{EXPERIMENTAL METHODS}

\section{A. Materials}

Ni100 and NiCo91, obtained from Kansai Catalyst Co., Ltd. (Japan), were calcined at 200, 250, 260, 270, 280, 290, and $300^{\circ} \mathrm{C}$. The morphology and crystallinity of the studied samples were investigated using a JSM6380LA system (JEOL, Japan) and a MultiFlex (Rigaku, Japan), respectively. The thermogravimetric-differential thermal analysis (TG-DTA) was carried out with DTG$60 \mathrm{AH}$ (Shimadzu, Japan). The amount of nickel and cobalt on the adsorbent was measured with an electronprobe microanalyzer (EPMA, JXA-8530F, JEOL, Japan), with an accelerating voltage of $45.0 \mathrm{kV}$ and a beam di- 

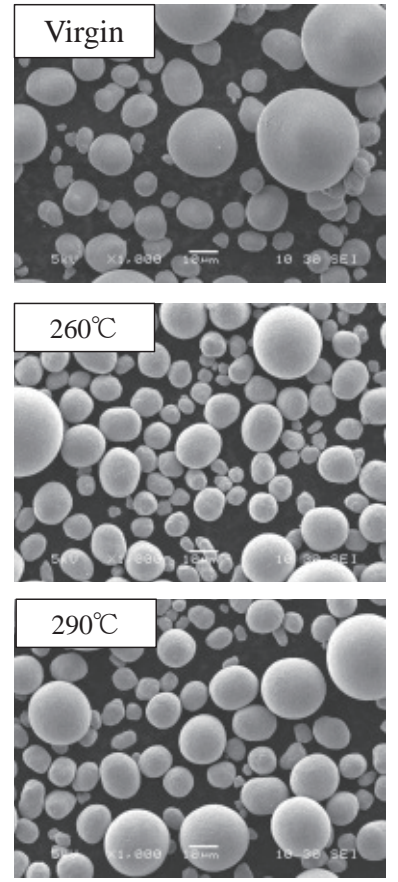
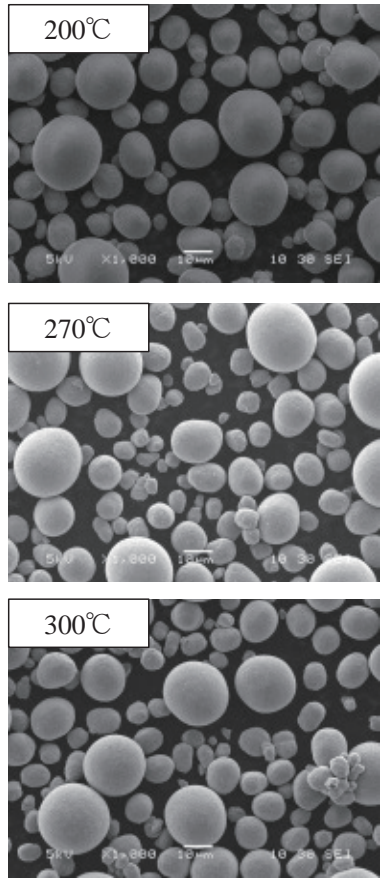
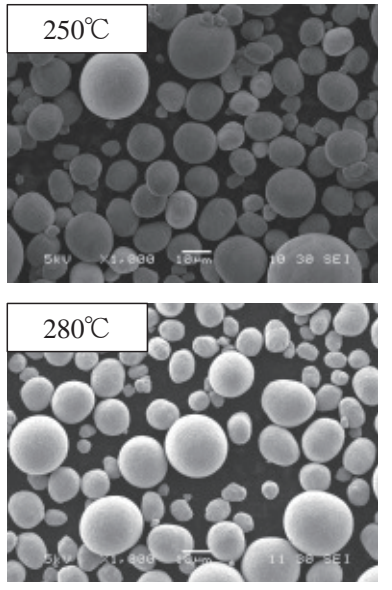

FIG. 1. SEM images of Ni100 at different temperatures. Scale bar is $10 \mu \mathrm{m}$.

ameter of $5 \mu \mathrm{m}$. The specific surface areas were measured with a specific surface analyzer (NOVA4200e, Yuasa Ionic, Japan).

\section{B. Adsorption of phosphate ion}

Adsorbent (1.0 g) was added to a solution $(300 \mathrm{~mL})$ containing phosphate ions (initial concentration was 500 $\mathrm{mg} / \mathrm{L})$. Suspensions were shaken at $100 \mathrm{rpm}$ for $24 \mathrm{~h}$ at $25^{\circ} \mathrm{C}$. Samples were filtrated through a $0.45 \mu \mathrm{m}$ membrane filter; the filtrate was then measured by the DR/890 colorimeter (Hach, USA). The amount of phosphate ions adsorbed was calculated with Eq. 1:

$$
X=\left(C_{0}-C_{e}\right) V / M
$$

where $X$ is the amount of phosphate ions adsorbed $(\mathrm{mg} / \mathrm{g}), \quad C_{0}$ is the concentration before adsorption $(\mathrm{mg} / \mathrm{L}), C_{e}$ is the concentration after adsorption $(\mathrm{mg} / \mathrm{L})$, $V$ is the volume of the solvent (L), and $M$ is the mass of the adsorbent $(\mathrm{g})$.

\section{RESULTS AND DISCUSSION}

\section{A. Properties of Ni100 and NiCo91 at different temperatures}

The SEM images displayed in Figs. 1 and 2 show that Ni100 and NiCo91 consist of spherical particles of various diameters. We observed that the calcination treatment hardly affected the surfaces of Ni100 and NiCo91. Moreover, the particle diameter of Ni100 was larger than that of NiCo91. The XRD patterns of Ni100 and NiCo91 are displayed in Figs. 3 and 4, respectively. The characteristic diffraction peaks at (001), (100), (101), (102), and (110) show that Ni100 and NiCo91 calcined below $250^{\circ} \mathrm{C}$ and have a $\beta$-type crystal structure [17]. The XRD patterns of the calcined samples at temperatures $>260^{\circ} \mathrm{C}$ exhibited sharper reflection peaks, indicating that a growth in the crystallite sizes of $\mathrm{NiO}$ has occurred. The characteristic diffraction peaks at (111), (200), (220), (311), and (222) suggested that Ni100 and NiCo91 calcined at temperatures $>260^{\circ} \mathrm{C}$ have a $\mathrm{NiO}$ structure. No peaks related to $\mathrm{Ni}(\mathrm{OH})_{2}$ were found, indicating that $\mathrm{Ni}(\mathrm{OH})_{2}$ was completely decomposed into $\mathrm{NiO}$ at $280^{\circ} \mathrm{C}[19]$. The XRD data of NiCo91 showed a similar trend to that of Ni100. Previous studies on heating nickel hydroxide materials have proposed two types of chemical reaction $[16$, 20]: i) dehydration (Equation 2), which corresponds to the loss of the adsorbed and/or structurally bonded water below $250^{\circ} \mathrm{C}$; ii) decomposition of nickel hydroxide to nickel oxide (Equation 3), when $\mathrm{Ni}(\mathrm{OH})_{2}$ is heated at temperatures $>250^{\circ} \mathrm{C}$.

Dehydration reaction:

$$
\mathrm{Ni}(\mathrm{OH})_{2}+X_{w} \mathrm{H}_{2} \mathrm{O} \rightarrow \mathrm{Ni}(\mathrm{OH})_{2}+X_{w} \mathrm{H}_{2} \mathrm{O}
$$

where $X_{w}$ is the moles of water. Decomposition reaction:

$$
\mathrm{Ni}(\mathrm{OH})_{2} \rightarrow \mathrm{NiO}+\mathrm{H}_{2} \mathrm{O}
$$

TG-DTA curves for Ni100 or NiCo91 are shown in Figs. 5 and 6, respectively. An endothermic peak at $270^{\circ} \mathrm{C}$ on the DTA curve of virgin Ni100 and NiCo91 was observed; the TG curve shows a sharp weight loss with $20 \mathrm{wt} \%$. This corresponds to the decomposition of $\mathrm{Ni}(\mathrm{OH})_{2}$ into $\mathrm{NiO}$ and $\mathrm{H}_{2} \mathrm{O}$. No peaks on the DTA curve of $\mathrm{Ni100}$ and $\mathrm{NiCo} 91$ calcined at $300^{\circ} \mathrm{C}$ were detected. This finding suggested that calcination in the range 250 $270^{\circ} \mathrm{C}$ can promote the conversion of $\mathrm{Ni}(\mathrm{OH})_{2}$ into $\mathrm{NiO}$, and that cobalt hardly affect the structure of the nickel 

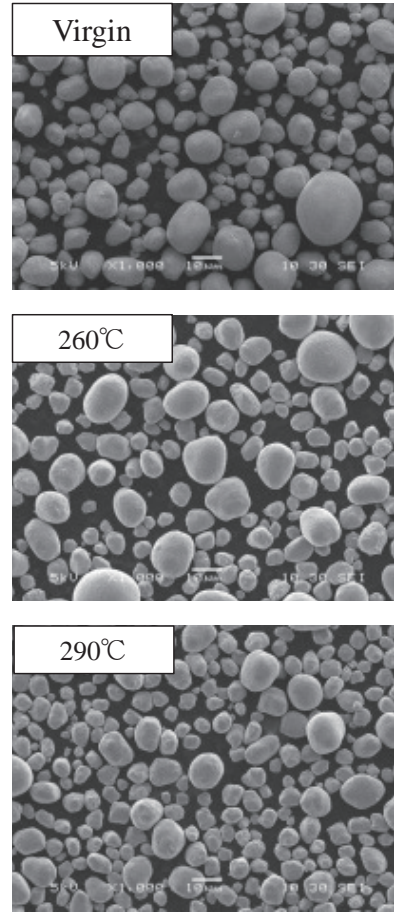
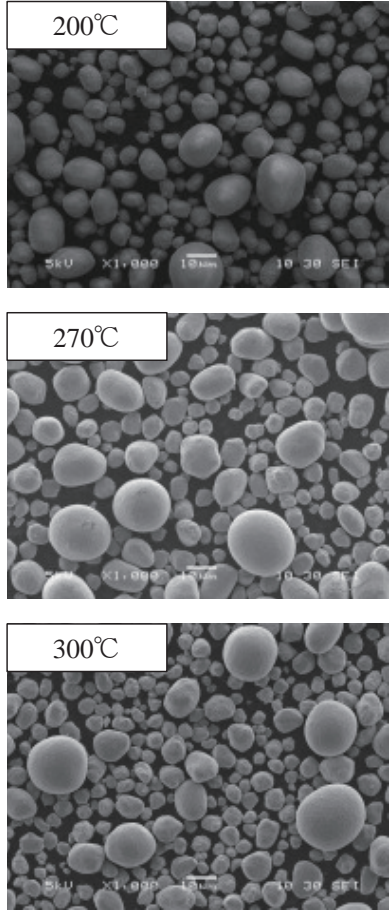
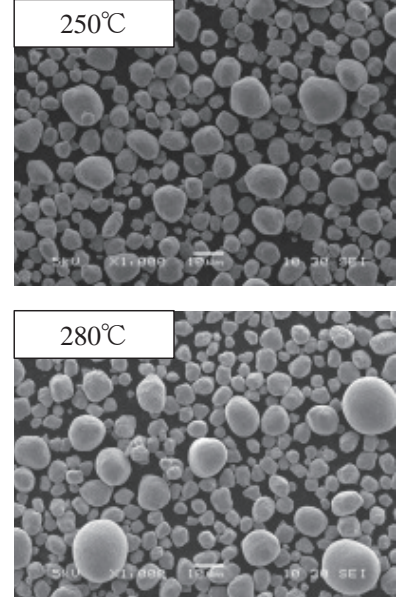

FIG. 2. SEM images of NiCo91 at different temperatures. Scale bar is $10 \mu \mathrm{m}$.

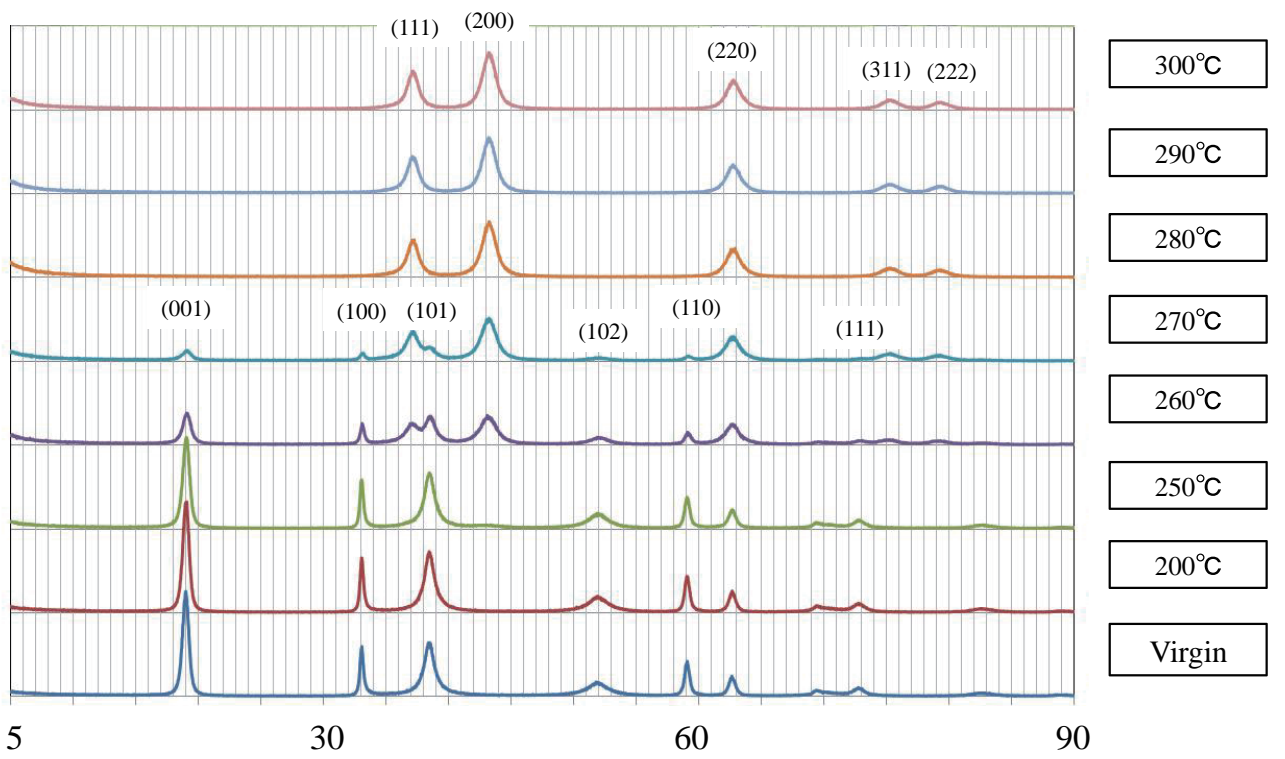

FIG. 3. XRD of Ni100 at different temperatures.

hydroxides. The relationship between the decomposition temperature and the crystallite size of the nickel hydroxides was also observed by Watanabe et al. [18, 21]. In addition, our data confirmed the presence of nickel and cobalt on the adsorbent (Fig. 7). The amount of cobalt onto the NiCo91 surface was larger than that onto Ni100, indicating that cobalt is present onto the NiCo91 surface. From the BET measurements (Table I), the specific surface areas of Ni100 and NiCo91 were determined to be in the range $17.9-148.3$ and $21.0-145.1 \mathrm{~m}^{2} / \mathrm{g}$, respectively. Our data showed that the specific surface areas increased suddenly at $260^{\circ} \mathrm{C}$. These results indicated that the presence of the $\mathrm{NiO}$ species affects increase the specific surface area of Ni100 or NiCo91 (from Figs. 2-5). Previous studies reported that the specific surface areas of microsized spherical $\mathrm{Ni}(\mathrm{OH})_{2}$, spherical $\mathrm{Ni}(\mathrm{OH})_{2}$, and nanostructures $\mathrm{Ni}(\mathrm{OH})_{2}$ are $10.8,10$, and $39.6 \mathrm{~m}^{2} / \mathrm{g}$, respectively $[22,23]$. These results suggest that Ni100 and NiCo91 calcined at different temperatures have a larger surface area; this can provide a high density of active sites, which, in turn, can promote the adsorption of materials from the aqueous solution. Therefore, obtaining a larger specific surface area can improve the application of these materials [17]. Addition of cobalt hardly affected 


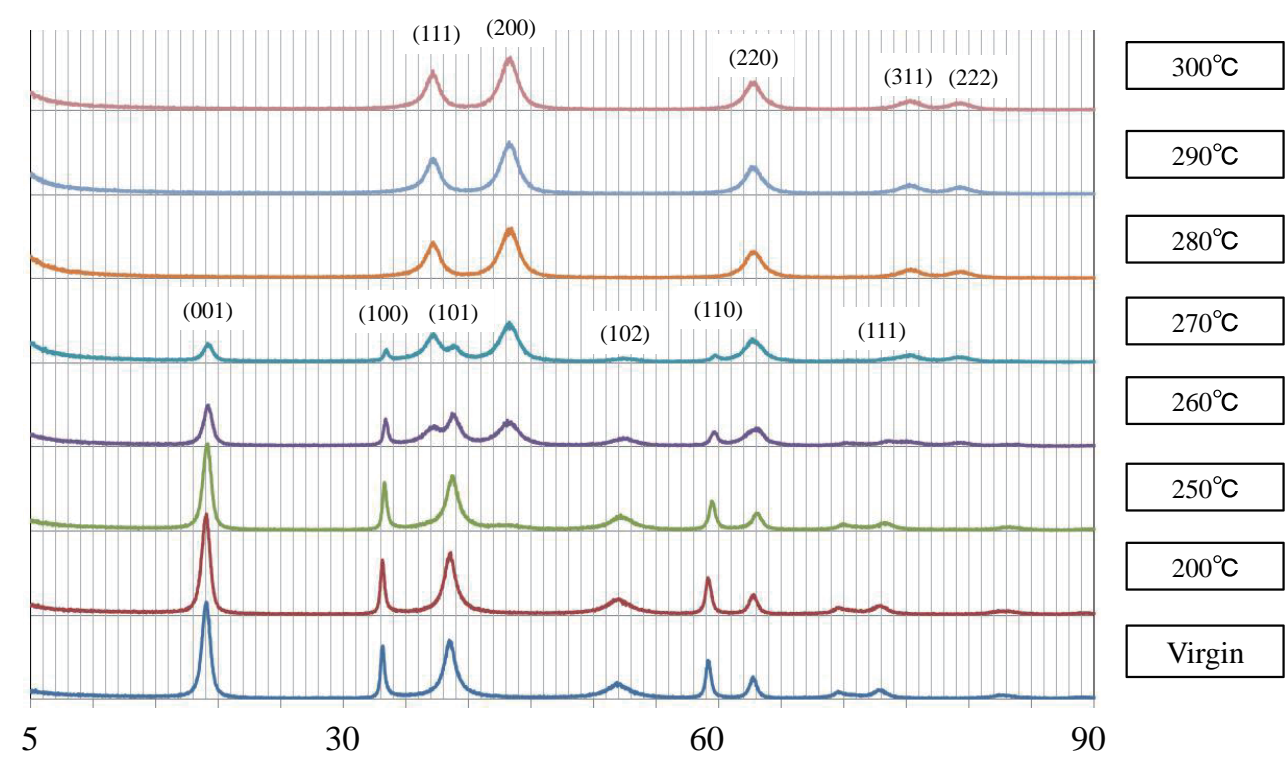

FIG. 4. XRD of NiCo91 at different temperatures.

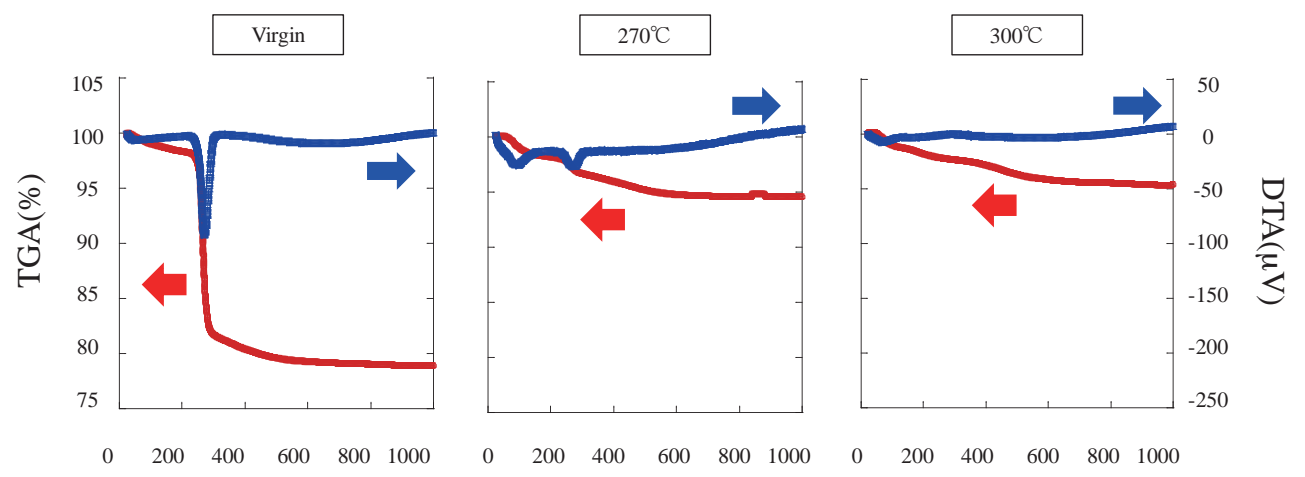

Temperatures $\left({ }^{\circ} \mathrm{C}\right)$

FIG. 5. TG-DTA of Ni100 at different temperatures.

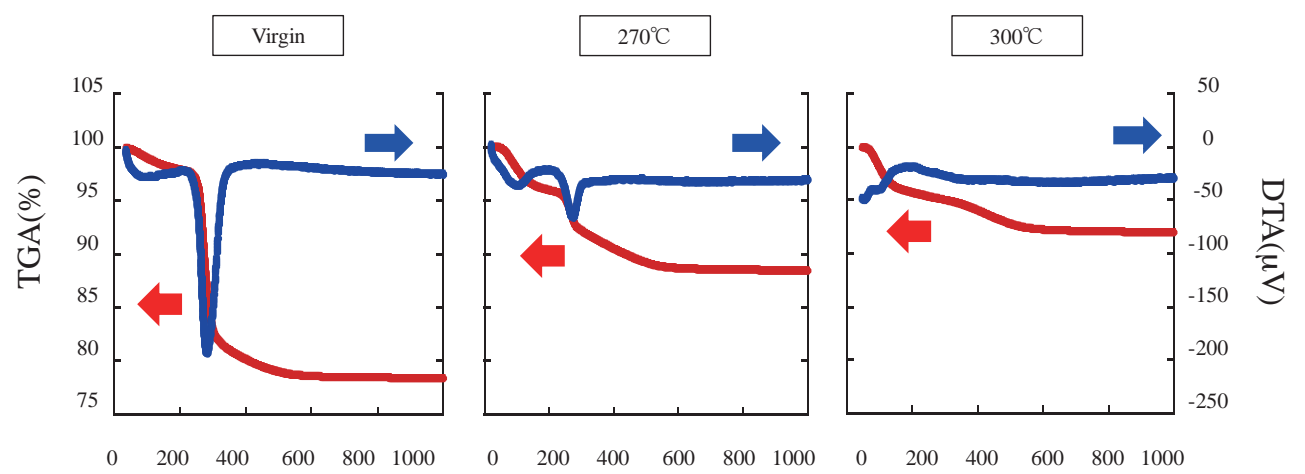

Temperatures $\left({ }^{\circ} \mathrm{C}\right)$

FIG. 6. TG-DTA of NiCo91 at different temperatures. 


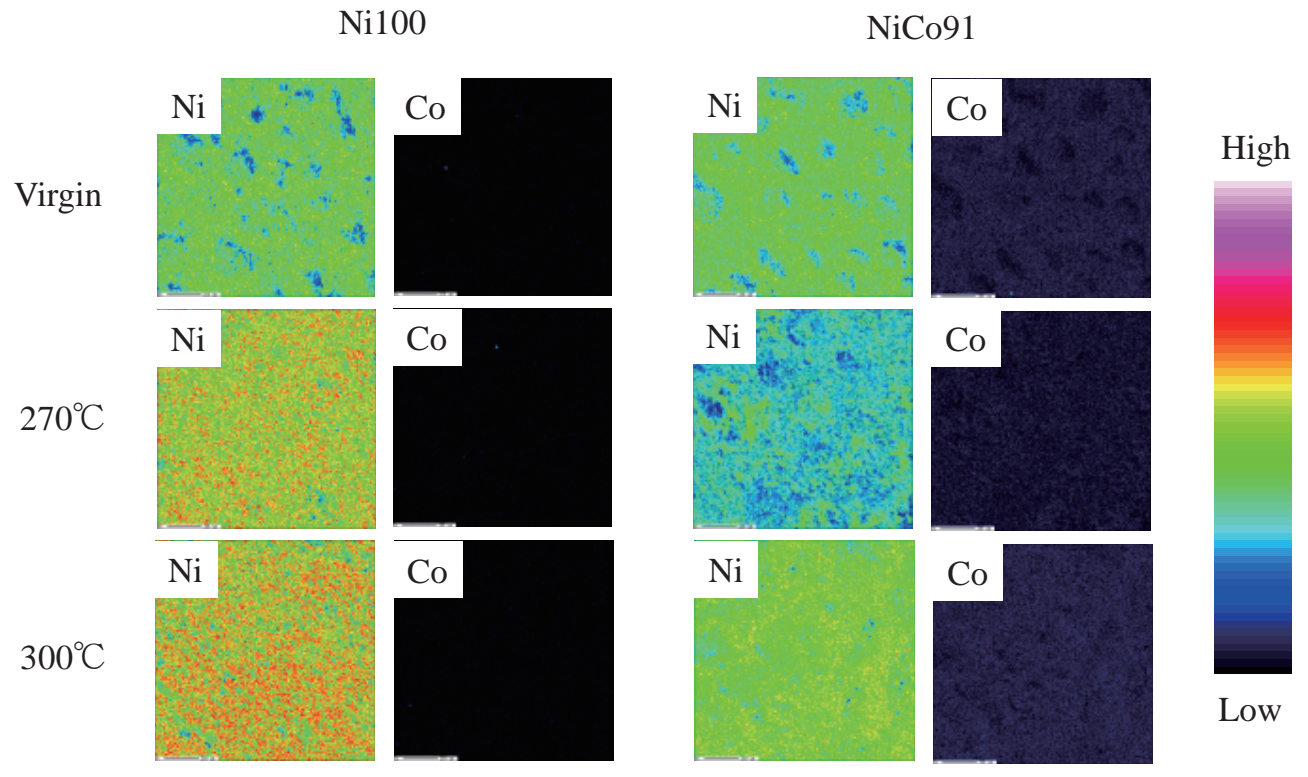

FIG. 7. Amount of nickel and cobalt onto adsorbent surface.

TABLE I. Specific surface area of Ni100 and NiCo91 at different temperatures.

\begin{tabular}{ccccccccc}
\hline \hline $\begin{array}{c}\text { Temperature } \\
\left({ }^{\circ} \mathrm{C}\right)\end{array}$ & Virgin & 200 & 250 & 260 & 270 & 280 & 290 & 300 \\
\hline $\begin{array}{c}\mathrm{Ni} 100 \\
\left(\mathrm{~m}^{2} / \mathrm{g}\right)\end{array}$ & 23.3 & 17.9 & 25.7 & 81.8 & 142.6 & 148.3 & 136.6 & 116.0 \\
\hline $\begin{array}{c}\mathrm{NiCo} 91 \\
\left(\mathrm{~m}^{2} / \mathrm{g}\right)\end{array}$ & 21.0 & 36.8 & 28.2 & 74.6 & 125.1 & 136.2 & 138.5 & 145.1 \\
\hline \hline
\end{tabular}

the specific surface areas.

\section{B. Adsorption of phosphate ions with Ni100 and NiCo91 at different temperatures}

As shown in Table II, the amount of phosphate ions adsorbed onto Ni100 and NiCo91 are in the range 29.2-44.7 and $29.7-54.0 \mathrm{mg} / \mathrm{g}$, respectively; these values are relatively large compared to those reported in previous studies (Table III), suggesting that Ni100 and NiCo91 have a significant potential for phosphate removal from aqueous solution [4, 24-26]. We also investigated the relationship between the specific surface area and the saturated amount of phosphate ions adsorbed (Fig. 8). The correlation coefficients of Ni100 and NiCo91 were determined to be 0.935 and 0.960 , respectively. A comparison of the adsorption capacities observed in this work and those from other studies is given in Table III [27-29]. The maximum adsorption capacity of the phosphate ions onto Ni100 and NiCo91 at different temperatures is in the range 29.2-44.7 and $29.7-54.0 \mathrm{mg} / \mathrm{g}$, respectively; the maximum adsorption capacities of phosphate ion onto various adsorbents different from those studied here were previously reported to be in the range $2.1-42.0 \mathrm{mg} / \mathrm{g}$. Thus, these data confirmed that Ni100 or NiCo91 can be considered as promising candidates for the adsorption of phosphate ions from aqueous solutions.

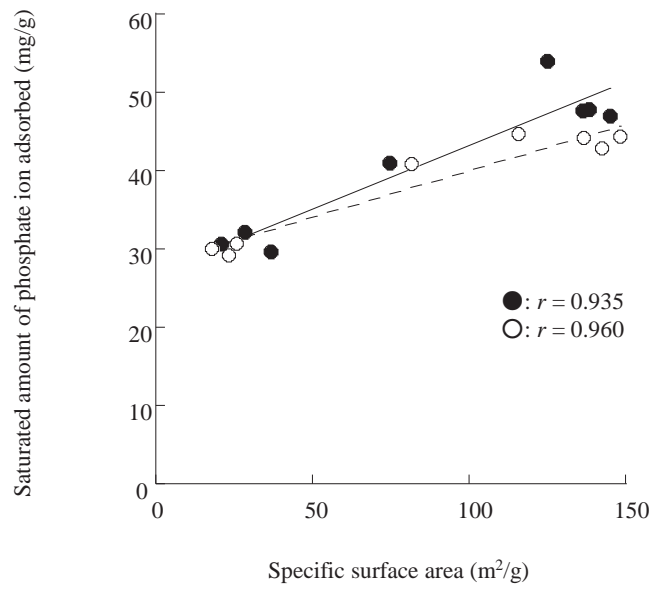

FIG. 8. Relationship between specific surface area and saturated amount of phosphate ion adsorbed. •: Ni100, ०: NiCo91.

TABLE II. Saturated amount of phosphate ion adsorbed onto Ni100 or NiCo91 at different temperatures.

\begin{tabular}{ccccccccc}
\hline \hline $\begin{array}{c}\text { Temperature } \\
\left({ }^{\circ} \mathrm{C}\right)\end{array}$ & Virgin & 200 & 250 & 260 & 270 & 280 & 290 & 300 \\
\hline $\begin{array}{c}\mathrm{Ni100} \\
(\mathrm{mg} / \mathrm{g})\end{array}$ & 29.2 & 30.0 & 30.7 & 40.9 & 42.8 & 44.3 & 44.2 & 44.7 \\
\hline $\begin{array}{c}\mathrm{NiCo} 91 \\
(\mathrm{mg} / \mathrm{g})\end{array}$ & 30.7 & 29.7 & 32.1 & 41.0 & 54.0 & 47.6 & 47.9 & 47.0 \\
\hline \hline
\end{tabular}

\section{CONCLUSIONS}

Nickel hydroxide (Ni100) and nickel hydroxide, including cobalt $(\mathrm{NiCo} 91)$, at different temperatures were prepared. The particle diameter of Ni100 was larger than that of NiCo91. The results of XRD and TG-DTA indicated that Ni100 and NiCo91 calcined between 250 and $270{ }^{\circ} \mathrm{C}$ can promote the conversion of $\mathrm{Ni}(\mathrm{OH})_{2}$ into $\mathrm{NiO}$. 
TABLE III. Comparison of adsorption capacity of various adsorbent for phosphate ion removal.

\begin{tabular}{ccc}
\hline \hline Adsorbent & Adsorption capacity (mg/g) & Reference \\
\hline Kanuma & 2.1 & 4 \\
Ferric sludge & 25.5 & 24 \\
Phosphate mine slime & 8.7 & 25 \\
Calcined waste egg shell & 42.0 & 26 \\
Thermal activated natural palygorskite & 23.0 & 27 \\
Red mud granular adsorbent & 6.6 & 28 \\
Granular boehmite & 36.9 & 29 \\
Ni100 at different temperatures & $29.2-44.7$ & This work \\
NiCo91 at different temperatures & $29.7-54.0$ & This work \\
\hline \hline
\end{tabular}

Moreover, cobalt hardly affected the structure of nickel hydroxides. The amount of cobalt adsorbed onto NiCo91 was larger than that onto Ni100. The specific surface areas of Ni100 and NiCo91 increased suddenly at $260{ }^{\circ} \mathrm{C}$. The amount of phosphate ions adsorbed onto Ni100 and NiCo91 showed a similar trend. A correlation between the specific surface areas of Ni100 and NiCo91 with the satu- rated amount of phosphate ions adsorbed was also found, the correlation coefficients being 0.935 and 0.960 , respectively. In conclusion, the findings presented in this work strongly indicate that Ni100 and NiCo91 can be considered as promising candidates for the adsorption of phosphate ions from aqueous solutions.
[1] D. J. Conley, H. W. Paerl, R. W. Howarth, D. F. Boesch, S. P. Seitzinger, K. E. Havens, C. Lancelot, and G. E. Likens, Science 323, 1014 (2009).

[2] J. Xiong, Z. He, Q. Mahmood, D. Liu, X. Yang, and E. Islam, J. Hazard. Mater. 153, 211 (2008).

[3] Y. Wang, T. Han, Z. Xu, G. Bao, and T. Zhu, J. Hazard. Mater. 121, 183 (2005).

[4] S. Yang, D. Ding, Y. Zhao, W. Huang, Z. Zhang, Z. Lei, and Y. Yang, J. Environ. Chem. Eng. 1, 355 (2013).

[5] I. Katz and C. G. Dosoretz, Desalination 222, 230 (2008).

[6] E. Vaiopoulou, P. Melidis, and A. Aivasidis, Desalination 213, 288 (2007).

[7] L. Ruixia, G. Jinlong, and T. Hongxiao, J. Colloid Interface Sci. 248, 268 (2002).

[8] E. C. Moreno and K. Varughese, J. Cryst. Growth 53, 20 (1981).

[9] X. Sun, T. Imai, M. Sekine, T. Higuchi, K. Yamamoto, A. Kanno, and S. Nakazono, J. Ind. Eng. Chem. 20, 3623 (2014).

[10] B. Pan, F. Han, G. Nie, B. Wu, K. He, and L. Lu, Environ. Sci. Technol. 48, 5101 (2014).

[11] L. Zhang, Y. Gao, Q. Zhou, J. Kan, and Y. Wang, Water Air Soil Pollut. 225, 1967 (2014).

[12] S. R. Ovshinsky, M. A. Fetcenko, and J. Ross, Science 260, 176 (1993).

[13] K. Ota, S. Mitsushima, S. Kato, S. Asano, H. Yoshitake, and N. Kamiya, J. Electrochem. Soc. 139, 667 (1992).

[14] V. Srinivasan and J. W. Weidner, J. Electrochem. Soc. 147, 880 (2000).
[15] A. M. Couper, D. Pletcher, and F. C. Walsh, Chem. Rev. 90, 837 (1990).

[16] C. Natarajan, H. Matsumoto, and G. Nogami, J. Electrochem. Soc. 144, 121 (1997).

[17] Q. S. Song, Y. Y. Li, and S. L. I. Chan, J. Appl. Electrochem. 35, 157 (2005).

[18] G. T. Zhou, Q. Z. Yao, X. Wang, and J. C. Yu, Mater. Chem. Phys. 98, 267 (2006).

[19] M. El-Kemary, N. Nagy, and I. El-Mehasseb, Mater. Sci. Semicond. Process. 16, 1747 (2013).

[20] B. Mani and J. P. Neufville, J. Electrochem. Soc. 135, 800 (1988).

[21] K. Watanabe, T. Kikuoka, and N. Kumagai, J. Appl. Electrochem. 25, 219 (1995).

[22] X. Liu and L. Yu, Mater. Lett. 58, 1327 (2004).

[23] A. M. Al-Enizi, A. A. Elzatahry, A. M. Abdullah, M. A. AlMaadeed, J. Wang, D. Zhao, and S. Al-Deyab, Carbon 71, 276 (2014).

[24] X. Song, Y. Pan, Q. Wu, Z. Cheng, and W. Ma, Desalination 280, 384 (2011).

[25] S. Jellali, M. A. Wahab, R. B. Hassine, A. H. Hamzaoui, and L. Bousselmi, Chem. Eng. J. 169, 157 (2011).

[26] F. Gan, J. Zhou, H. Wang, C. Du, and X. Chen, Water Res. 43, 2907 (2009).

[27] T. E. Kose and B. Kivanc, Chem. Eng. J. 178, 34 (2011).

[28] Y. Zhao, Q. Yue, Q. Li, X. Xu, Z. Yang, X. Wang, B. Gao, and H. Yu, Chem. Eng. J. 193-194, 161 (2012).

[29] F. Ogata, H. Tominaga, Y. Iwata, A. Ueda, Y. Tanaka, and N. Kawasaki, J. Water Environ. Technol. 11, 225 (2013). 